\title{
Antigen specific serum antibody response to Chlamydia trachomatis in patients with acute pelvic inflammatory disease
}

\author{
A Miettinen, P K Heinonen, K Teisala, R Punnonen, J Paavonen
}

\begin{abstract}
Sera from 35 patients with acute pelvic inflammatory disease (PID) with and without Chlamydia trachomatis confirmed by culture and sera from 19 control patients with neither evidence of pelvic infection nor $C$ trachomatis infection were studied for the presence of serum IgG, IgA, and IgM antibodies to $C$ trachomatis using enzyme immunoassay (EIA) and immunoblotting techniques. There was no correlation between the antibody concentrations in the EIA and the spread of chlamydial infection, as determined by cervical, endometrial, and laparoscopic sampling for chlamydia. The immunoblot analysis showed antibodies to the major outer membrane protein (MOMP) of $C$ trachomatis elementary bodies in all patients who had had $C$ trachomatis isolated. Reactivity was also frequently observed against the $68,62,60,45$, and 31 kilodalton antigens. About 20 antigenic polypeptides were identified. Differences in antibody prevalence to specific chlamydial antigens, however, were not related to the site of chlamydial isolation or serum antibody concentrations observed with the EIA.
\end{abstract}

The results indicate that patients with PID with and without upper genital tract infection with $C$ trachomatis cannot be differentiated by reactivity of sera to specific chlamydial polypeptide antigens. The determination of a specific serum IgA antibody response by EIA was the most effective single test to discriminate between patients with and without acute chlamydial infection.

Department of Biomedical Sciences, University of

Tampere, PO Box 607, SF-33101 Tampere,

Finland

A Miettinen

Department of

Clinical Sciences,

University of Tampere

J Paavonen

Department of

Obstetrics and

Gynecology,

University Central

Hospital of Tampere

P K Heinonen

$\mathrm{K}$ Teisala

R Punnonen

Correspondence to:

Dr A Miettinen

Accepted for publication

1 May 1990

Tubal damage caused by pelvic inflammatory disease (PID) is an important cause of involuntary infertility and ectopic pregnancy. ${ }^{1}$ Chlamydia trachomatis has been isolated from the fallopian tubes of women with acute PID, and serological studies have confirmed the importance of the organism in this disorder. Raised serum concentrations of chlamydial antibodies are commonly seen in patients with complicated genital tract infections, such as PID. The usefulness of serological methods in the diagnosis of acute chlamydial infections is, however, limited by the persistence of antibodies from previous infection. ${ }^{2}$ Recent studies have suggested that there is a distinctive antigen specific humoral immune res- ponse in patients with tubal infertility caused by previous chlamydial PID. ${ }^{34}$

In this study we investigated the serological response in patients with PID by enzyme immunoassay (EIA) and immunoblotting techniques. The findings were correlated with culture of $C$ trachomatis from different genital tract sites. We were interested to see whether a distinctive antibody response could be identified in association with acute upper genital tract infection with $C$ trachomatis.

\section{Methods}

The study population comprised 45 women with suspected acute PID who presented consecutively at the Department of Obstetrics and Gynecology, University Central Hospital, Tampere, Finland, between June 1983 and June 1984. All patients were admitted and underwent laparoscopy and endometrial biopsy. C trachomatis, Neisseria gonorrhoeae, Mycoplasma hominis, Ureaplasma urealyticum, facultative and anaerobic bacteria and herpes simplex virus were isolated from specimens collected from the cervix, endometrium, fallopian tubes and cul-de-sac and were identified as described. ${ }^{56}$ Altogether, 35 patients had either laparoscopic evidence of salpingitis or histopathological evidence of endometritis and are referred to in the text as patients with PID. The laparoscopic findings in the 10 women who did not have PID were as follows: ovarian cyst in six, pelvic adhesions in two, ectopic pregnancy in one and periappendicular abscess in one. They were treated in the study as control patients. Additionally, 11 voluntary patients undergoing laparoscopic tubal sterilisation were enrolled as controls.

\section{ENZYME IMMUNOASSAY TECHNIQUE}

Serum $\operatorname{IgG}, \operatorname{IgA}$, and $\operatorname{IgM}$ antibodies to $C$ cial kit (Chlamydia trachomatis IgG; Labsystems Ltd, Helsinki, Finland). The IgA and IgM antibodies were measured by substituting the provided anti-human IgG conjugate with rabbit anti-human IgA and IgM conjugates (Dakopatts A/S, Denmark). The bound rabbit antibodies were detected by horseradish peroxidase-conjugated anti-rabbit antibodies produced in swine serum (Dakopatts). The principle behind the expression of antibody concentrations as relative EIA units (EIU) has been described in detail elsewhere. ${ }^{7}$ In the IgG assay the cut off level for seropositivity was set according to the manufacturer's instructions. The recommended cut off level of 60 EIU 
Figure 1 Distribution of serum IgG antibody concentrations to

Chlamydia trachomatis in sera from 35 women with acute PID from whom the organism was isolated in 17 and not in 18, and in the sera of 19 controls who had neither evidence of chlamydial infection.

Vertical bars denote mean ( $\pm S D)$ concentrations. pelvic infection nor



roughly corresponded with the mean $(+2 \mathrm{SD})$ of the control patients. In the modified IgA and IgM assays the cut off levels for seropositivity were determined as the mean ( $+3 \mathrm{SD})$ of the control patients.

\section{IMMUNOBLOTTING TECHNIQUE}

Partly purified $\mathrm{L}_{2}^{8}$ elementary bodies of $C$ trachomatis serotype (kindly provided by $\mathrm{Dr} \mathrm{K}$ Kahma, Orion Diagnostica Ltd, Espoo, Finland) were solubilised by incubation at $100^{\circ} \mathrm{C}$ for three minutes with sodium dodecyl sulphate (SDS) and 2-mercaptoethanol and electrophoresed in $10 \%$ SDS-polyacrylamide gel. ${ }^{9}$ For estimation of molecular weight standard proteins (Low Molecular Weight Calibration Kit; Pharmacia, Sweden) were included in each electrophoretic run. Electrophoretically separated components of the organism were transferred on to nitrocellulose paper. ${ }^{10}$ After electrotransfer the paper was immersed in $5 \%$ fetal calf serum (FCS) for 30 minutes to block non-specific binding of antibody. The paper was subsequently immersed in human sera diluted in $1 / 100$ in phosphate buffered saline containing $5 \%$ FCS for 30 minutes on a rocker platform. Bound antibodies were detected by peroxidase-labelled antibody to human IgG, IgA, and IgM (Dakopatts). The peroxidase substrate diaminobenzidine (Sigma, St Louis, Missouri, USA) and hydrogen peroxide were then added to visualise the antibody binding.

Figure 2 Distribution of serum Ig $A$ antibody concentrations to $C$ trachomatis in ser a from 35 women with acute PID in whom the organism was isolated in 17 and not in 18 , and the sera of 19 controls who had neither evidence of pelvic infection nor chlamydial infection. Vertical bars denote mean $( \pm S D$ ) concentrations.

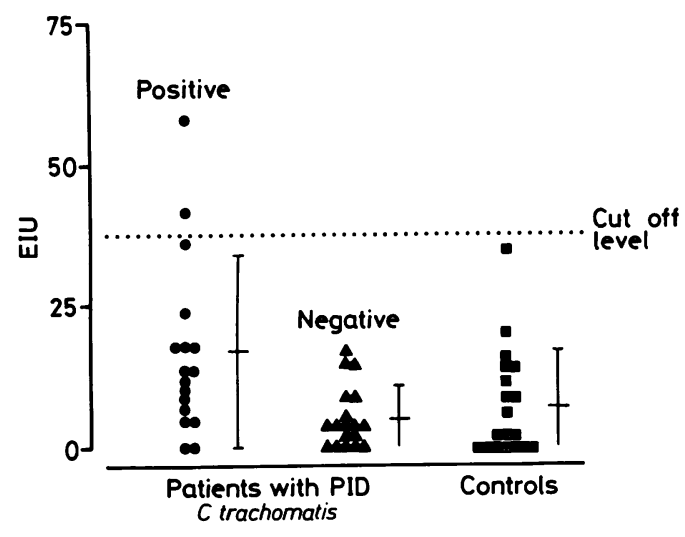

Figure 3 Distribution of serum IgM antibody concentrations to $C$ trachomatis in sera from 35 women with acute PID in whom the organism was isolated in 17 and not in 18, and in the sera of 19 controls who had neither evidence of pelvic infection nor chlamydial infection. Vertical bars denote mean $( \pm S D)$ concentrations.

Fisher's exact test was used for statistical comparisons.

\section{Results}

$C$ trachomatis was isolated from the cervix in 17 $(49 \%)$ of 35 patients with PID. $C$ trachomatis was isolated from the endometrium in six patients and from the endometrium and fallopian tubes in five patients. One of the 10 patients without PID and one of the 11 women undergoing sterilisation had positive cervical cultures for $C$ trachomatis and were excluded from the serological control group. The control group thus comprised 19 cases with no evidence of pelvic infection or $C$ trachomatis infection.

Significantly higher mean IgG, IgA, and IgM antibody titres were shown in patients with $C$ trachomatis confirmed by culture than in those without confirmation by culture or controls, using the EIA. Positive concentrations of IgG antibodies occurred in nine $(53 \%)$ of the 17 patients with $C$ trachomatis confirmed by culture, compared with two $(11 \%)$ of the 18 patients without $C$ trachomatis $(\mathrm{p}=0.0089)$, and with two $(11 \%)$ of the 19 controls $(\mathrm{p}=0.0069)$ (fig 1). In the EIA for IgA antibodies $11(65 \%)$ of the 17 patients with $C$ trachomatis isolated compared with only two $(11 \%)$ of the 18 patients without $C$ trachomatis isolated ( $p=0.0012)$, and none of the 19 controls $(p=0.00002)$ showed positive antibody concentrations (fig 2). Of the 13 cases positive for IgA antibodies, $10 .(77 \%)$ showed positive concentrations of IgG antibodies $(\mathrm{p}=0.000079)$. In the EIA for IgM antibodies the distribution of the antibody concentrations did not differ significantly among the groups (fig 3).

Among the 17 patients who had $C$ trachomatis isolated from the genital tract, no correlation was found between the mean concentrations or the occurrences of positive concentrations of chlamydial antibodies in the EIA and the site of chlamydial isolation. Four out of five patients who had $C$ trachomatis in the fallopian tubes, five out of seven patients who had $C$ trachomatis in the endometrium, and four out of five patients who had chlamydia 
Figure 4 Immunoblot pattern of serum $\operatorname{IgG}$ antibodies from 17 PID patients from whom $C$ trachomatis was isolated from the fallopian tubes in five, from the endometrium in six, and from the lower genital tract only in six. The position of molecular weight markers are indicated to the left. Serum EIA antibody concentrations are shown below the strips as relative units (EIU).

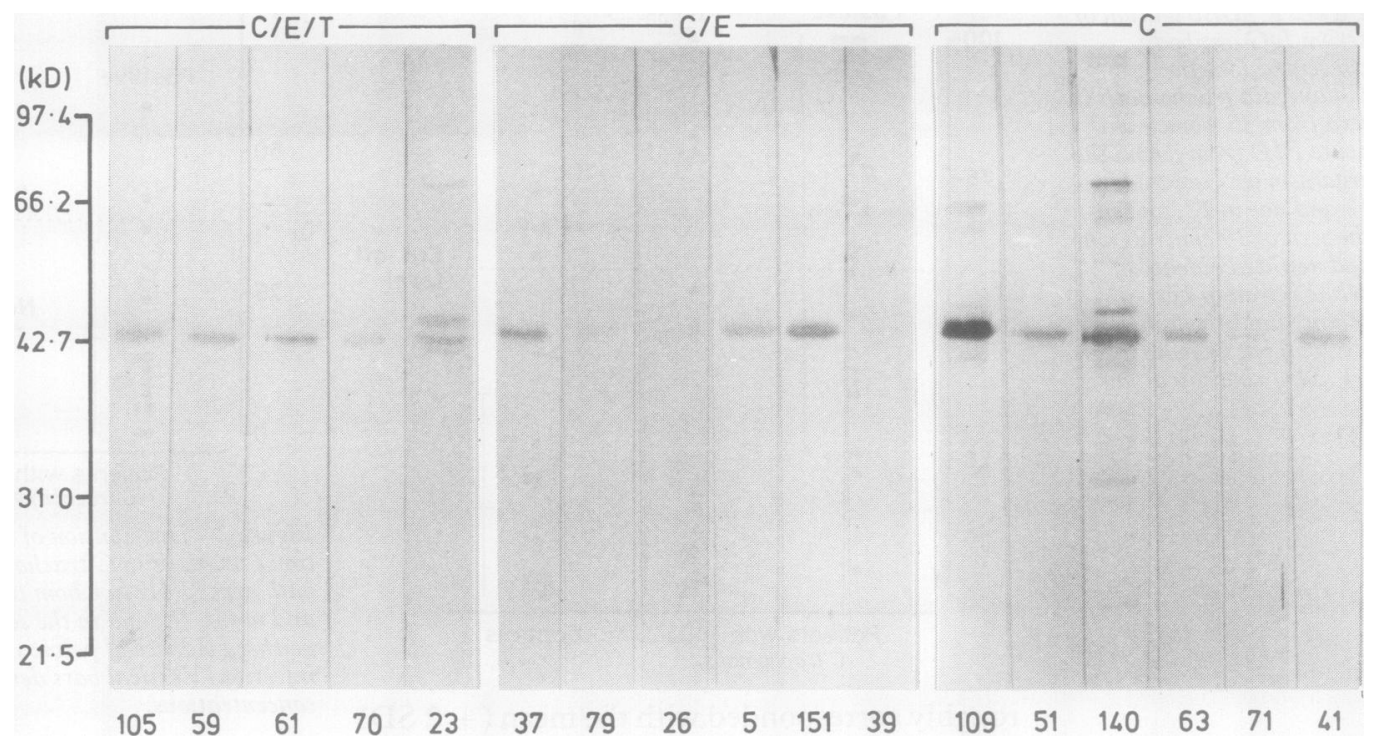

isolated from the lower genital tract had positive serum IgG or IgA antibody concentrations, or both.

With the immunoblot analysis, IgG antibodies were detected in all and IgA antibodies in four $(24 \%)$ of the 17 patients who had $C$ trachomatis confirmed by culture. IgM antibodies were not detected. In the IgG class about 20 chlamydial polypeptide antigens were recognised. The major outer membrane protein (40 kilodaltons) of elementary bodies was immunodominant in all IgG and IgA positive subjects. Among serum antibodies in the IgG class reactivity was also observed with $68,62,60,45$, and 31 kilodalton antigens (fig 4). Among serum antibodies in the IgA class reactions with 68,60 , and 45 kilodalton antigens were observed (data not shown). The number and occurrence of specific antigenic polypeptides was not related to the extent of chlamydial infection, as determined from the sites of positive chlamydial isolation. Moreover, there was no correlation between the number of antigenic polypeptides detected and the antibody concentrations in the EIA (fig 4).

\section{Discussion}

Several different tests, including complement fixation, various immunofluorescence tests (micro-IFAT, inclusion IFAT), and EIAs, are currently used to determine chlamydial antibodies. Depending on the antigen used, these tests probably measure antibodies against different antigenic determinants of Chlamydia species, and differ considerably in sensitivity and specificity. So far, the value of antibody assays in the diagnosis of chlamydial infections is limited both by their poor performance in superficial mucosal infections and by the persistence of antibody from previous infection.

We applied a modification of the EIA using reticulate bodies of $C$ trachomatis serotype $\mathrm{L}_{2}$ as antigen to determine the immunoglobulin class specific antibody response in women with PID. High positive serum IgG antibody concentrations were found in $53 \%$ of such patients, but equally high antibody concentra- tions also occurred among patients with PID who did not have $C$ trachomatis confirmed by culture, and among apparently healthy controls, probably reflecting previous chlamydial infections. The determination of chlamydial IgA antibodies proved an equally sensitive and yet more specific test than the determination of IgG antibodies in diagnosing acute chlamydial infection. There were no IgA positive cases among the control patients. Among the patients with PID in whom $C$ trachomatis was not isolated the occasional IgA positive cases detected were very distinct, associated with positive IgG antibody concentrations and, conceivably, as a result of previous chlamydial infection. The determination of IgM antibodies did not provide any additional information. Regarding chlamydial IgG antibodies, our findings thus correspond to what has previously been reported on the occurrence of chlamydial antibodies in PID. ${ }^{11-13}$ The current findings provide additional evidence to support the concept that specific short lived serum IgA antibodies may be a potential marker of active chlamydial infection. ${ }^{14} 15$ The sensitivity of the described EIA does not, however, validate the test to be used as a sole criterion for treatment, as it only detected $65 \%$ of those infected.

The differences among antibody concentrations in patients with PID did not correlate with the site of chlamydial isolation. Patients with PID who had $C$ trachomatis isolated from the lower genital tract showed high antibody concentrations in the EIA as often as those with $C$ trachomatis isolated from the endometrium or fallopian tubes. In contrast, we have shown that in patients with PID in whom $N$ gonorrhoeae is isolated, the concentrations of specific serum IgM antibodies in particular, and to some extent, the concentrations of $\operatorname{IgA}$ correlate with the extent of gonococcal infection. ${ }^{7}$ It is conceivable that different mechanisms in the pathogenesis of gonococcal and chlamydial PID account for the differences in antibody response. The current findings thus support the widely adopted concept that $C$ trachomatis should be regarded as a probable cause of PID if isolated from the genital tract.

In the immunoblotting analysis a protein 
with a molecular weight of about 40 kilodaltons-that is, the MOMP of $C$ trachomatis $^{16}$ - was the principal immunoreactive component observed in all positive IgG and IgA antibody responses. About 20 other antigenic polypeptides were also identified, although these minor reactions were not seen in all cases. We were unable to confirm any consistent immunoblotting pattern or specific antigenic components that would discriminate between patients with PID with or without $C$ trachomatis isolated from the upper genital tract.

The differences in antibody prevalence to specific chlamydial antigens were not generally related to the antibody concentrations observed with the EIA. The different antigens being used in the test systems probably account for this discrepancy. In the EIA, lipopolysaccharides or other broadly reactive antigenic components may have detected antibodies not reacting with the serotype specific protein antigens in the immunoblotting test. In both tests the antigens were derived from the $\mathrm{L}_{2}$ serotype of $C$ trachomatis, which, although it shows broad cross-reactivity among chlamydial strains, ${ }^{17}$ would not produce genital infections in the community affected. Thus it is unlikely that a serotype specific antibody response would be detected, which explains the lower sensitivity of the immunoblotting test in our study.

In previous studies, reaction against the MOMP has been shown to dominate the IgG and $\operatorname{IgA}$ antibody responses in men and women with chlamydial urethritis and in women with cervicitis. ${ }^{1819}$ Our data indicate that cervical, endometrial, and tubal infection by $C$ trachomatis induce an overlapping and indistinguishable serological response to chlamydial polypeptide antigens. In future studies on the serodiagnosis of chlamydial infections the determination of the affinity or the subclasses of the $\operatorname{IgG}$ and $\operatorname{IgA}$ antibody responses, or both, should be attempted.

The technical assistance of Ms Mervi Autio is gratefully acknowledged. The study was supported by a grant from the Academy of Finland (7939/304/83)
1 Weström L. Incidence, prevalence and trends of acute pelvic inflammatory disease and its consequences in indusinflammatory disease and its consequences in indus-
trialized countries. Am JObstet Gynecol 1980;138:880-92.

2 Puolakkainen M, Vesterinen E, Purola E, Saikku P, Paavonen J. Persistence of chlamydial antibodies after pelvic inflammatory disease. J Clin Microbiol 1986; 23:924-8

3 Brunham RC, Maclean IW, Binns B, Peeling RW. Chlamydia trachomatis: its role in tubal infertility. $J$ Infect Dis 1985;152:1275-82.

4 Brunham RC, Peeling R, Maclean I, McDowell J, Persson $\mathrm{K}$, Osser S. Postabortal Chlamydia trachomatis salpingitis: Correlating risk with antigen-specific serological responses and neutralization. J Infect Dis 1987;155: $749-55$.

5 Paavonen J, Aine $\mathrm{R}$, Teisala $\mathrm{K}$, et al. Chlamydial endometritis. J Clin Pathol 1985;38:726-32.

6 Paavonen J, Teisala K, Heinonen PK, et al. Microbiological and histopathological findings in acute pelvic inflam matory disease. Br J Obstet Gynaecol 1987;94:454-60.

7 Miettinen A, Hakkarainen K, Grönroos P, et al. Classspecific antibody response to gonococcal infection. J Clin Pathol 1989;42:72-6.

8 Wahlström E, Väänänen P, Saikku P, Nurminen M. Processing of McCoy cell cultures infected with Chlamydia trachomatis: sequential isolation of elementary bodies and lipopolysaccharide. Fems Microbiol Lett 1984;24: $179-83$.

9 Laemmli UK. Cleavage of structural proteins during the assembly of the head of bacteriophage T4. Nature assembly of the

10 Towbin H, Staehelin T, Gordon J. Electrophoretic transfer of proteins from polyacrylamide gels to nitrocellulose sheets: Procedure and some applications. Proc Natl Acad Sci USA 1979;76:4350-4.

11 Paavonen J, Saikku P, Vesterinen E, Aho K. Chlamydia trachomatis in acute salpingitis. $\mathrm{Br} J$ Vener $\mathrm{Dis} 1979$ 55:203-6.

12 Treharne JD, Ripa KT, Mårdh P-A, Svensson L, Weström L, Darougar S. Antibodies to Chlamydia trachomatis in acute salpingitis. Br J Vener Dis 1979;55:26-9.

13 Terho P, Meurman O. Chlamydial serum IgG, IgA, and local IgA antibodies in patients with genital-tract infeclocal IgA antibodies in patients with genital-tract infecMicrobiol 1981;14:77-87.

14 Cevenini R, Sarov I, Rumpianesi F, et al. Serum specific IgA antibody to Chlamydia trachomatis in patients with chlamydial infections detected by ELISA and an immunofluorescence test. J Clin Pathol 1984;37:686-91.

15 Hanuka N, Glasner M, Sarov I. Detection of IgG and IgA antibodies to Chlamydia trachomatis in sera of patient with chlamydial infections: use of immunoblotting and immunoperoxidase assays. Sex Transm Dis 1989;15:93-9.

16 Caldwell HD, Kromhout J, Schachter J. Purification and partial characterization of the major outer membrane protein of Chlamydia trachomatis. Infect Immun 1981; 31:1161-76.

17 Reeve P, Gerloff RK, Casper E, Philip RN, Oriel JD, Powis PA. Serological studies on the role of Chlamydia in the PA. Serological studies on the role of Chlamydia in the aetiology of $n$

18 Cevenini R, Rumpianesi F, Sambri V, La Placa M. Antigenic specificity of serological response in Chlamydia trachomatis urethritis detected by immunoblotting. J Clin Pathol 1986;39:325-7.

19 Cevenini R, Rumpianesi F, Donati M, Moroni A, Sambri V, La Placa M. Class specific immunoglobulin response to individual polypeptides of Chlamydia trachomatis, elementary bodies, and reticulate bodies in patients with chlamydial infection. J Clin Pathol 1986;39:1313-16. 